\title{
Mutagenesis Analysis of ABCG2 Gene Promoter of Zebrafish (Danio Rerio)
}

\author{
NABILA ZURAIN BINTI MD YUSNI, LEONARD WHYE KIT LIM \& HUNG HUI CHUNG*
}

Faculty of Resource Science and Technology, Universiti Malaysia Sarawak, 94300 Kota Samarahan, Sarawak Malaysia.

*Corresponding author: hhchung@unimas.my

\begin{abstract}
Breast cancer is the commonest cancer among women worldwide and the probability of a woman dying from breast cancer is high (about 1 in 38 of total human population (2.6\%)). The main factor for mortality is due to the resistance of this particular disease to chemotherapeutic agents. One of the most well-known proteins to be found to correlate significantly with breast cancer resistance to chemotherapeutic agent is the ATP-binding cassette super-family G member 2 (ABCG2). Knowledge on ABCG2 gene regulation is still lacking in terms of how the increased cytotoxic levels are closely related to induce a hype in gene transcript levels and ultimately cause of the reduction in chemotherapeutic agents. The approach taken in this study is through mutational analysis of selected transcription factor governing the expression of $A B C G 2$. In order to achieve this, a previously cloned ABCG2 promoter which has been isolated (around 1500 bp in size) from Danio rerio and inserted into pGL3.0 plasmid, was subjected to site-directed mutagenesis. Selected transcription factor which is AP-1 was successfully mutated by deletion of 5'- TGACGCG -3' sequence at position $1113 \mathrm{bp}$ from TSS +1 where it would bind in order to define their role in $A B C G 2$ physiological function. Sequencing result after site-directed mutagenesis shows high similarities about $98 \%$ with $A B C G 2$ gene of Danio rerio. Upon validation, it was found that the intended AP-1 binding site has been mutated. In future work, the mutated clone here will be subjected to transfection analysis where dual-luciferase assay will be conducted to verify the loss of activity from the $A B C G 2$ promoter upon mutation of the targeted AP-1 site. Hence, the mutagenesis analysis of ABCG2 promoter are able to provide information on the involvement of AP-1 transcription factor in multidrug resistance mechanism of breast cancer and thus will be a potential target for chemotherapeutic agent.
\end{abstract}

Keywords: Danio rerio, ABCG2 promoter, site-directed mutagenesis, transcription factor, xenobiotics

Copyright: This is an open access article distributed under the terms of the CC-BY-NC-SA (Creative Commons Attribution-NonCommercial-ShareAlike 4.0 International License) which permits unrestricted use, distribution, and reproduction in any medium, for non-commercial purposes, provided the original work of the author(s) is properly cited.

\section{INTRODUCTION}

About one in 20 women in the Malaysia suffers from breast cancer and the disease rate varied across the three main races, the Malays, the Chinese and the Indians (Yip, Bhoo, \& Teo, 2014). ATP-binding cassette super-family G member 2 ( $A B C G 2)$ gene expression showing correlation with grade of tumor advancement and high ABCG2 gene expression level is associated with poor survival in early stage breast cancer patients (Maciejczyk et al., 2012). ABCG2 protein is well known as one of the ATP-binding cassette transporters (ABC transporters) which is capable to act as multidrug resistance because of its potential role in protecting the breast cancer stem cells (Mo \& Zhang, 2012).

According to $\mathrm{Hu}$ et al. (2020), ABCG2 protein may produce resistance to chemotherapeutic agents. ABCG2 protein is responsible to control the movement of harmful and beneficial substrates such as flavonoids and phytoestrogens across the intestinal cells into the intestinal lumen. Therefore, inhibition of carcinogen substrate presence in living tissue will reduce the absorption of carcinogen substrates from the diet (Andersen et al., 2015). At the same time, ABCG2 function in transferring the chemotherapeutic drugs out of the cells and keeping the intracellular drug compound below the toxic level (Sukowati, 2012).

The functional characterization of ABCG2 gene has been reported before on members of Danioninae like Sarawak rasbora and zebrafish (Kobayashi et al., 2008; Lim et al., 2018a). In addition, an in vivo spatiotemporal expression analysis has been conducted lately by Lim and Chung (in press) on ABCG2 gene promoters in zebrafish 
embryos. The research on the gene regulation of $A B C G 2$ is still considered scarce in spite of the highlights on the contribution of regulatory agents towards gene activation (Hernandez-Garcia \& Finer, 2014; Lim, Chung, Chong, \& Lee, 2018b; 2019a; 2019b; Liu \& States, 2002; Mishra, Dhanda, Siwach, Aggarwal, \& Jayaram, 2020; Wang, Cheng, Li, Wu, \& Zhao, 2018). The detailed molecular mechanism of such gene expression still remains largely unknown especially how the increase in cytotoxic level may in turn induce a hype in gene transcript level which eventually leads to the lowering of chemotherapeutic agent. This research focuses on the potential transcription factor candidate in $A B C G 2$ gene regulation which provides complex feedback regulation and allows different physiological response under various circumstances. Previously, trans-factors regulating ABC genes such as Sp1, Sp3, p53 and AP-1 were identified. Hence it is postulated that site directed mutagenesis will help to identify critical transcription factors and determine their role in regulating ABCG2 by introducing specific nucleotide changes.

\section{MATERIALS \& METHOD}

\section{DNA extraction, PCR and cloning}

The upkeep of fish and fish tissue yielding were performed with compliance to the approval and regulations established by the Universiti Malaysia Sarawak Animal Ethics Committee (UNIMAS/TNC(PI)-04.01/06-09(17)). Total DNA extraction from whole body of an adult zebrafish was done following the protocols formulated by Chung (2018). Gradient PCR targeting the ABCG2 gene promoter was conducted as described by Lim, Chung, and Hasnain (2020) with adjustment on the extension time to $1.5 \mathrm{~min}$. The cloning procedures were mirrored from that of Jee et al. (2017). The plasmid used to house the promoter gene insert is the pGL3.0 (Promega, USA). Sequence verification was done via sequencing and bioinformatic query against NCBI BLAST.

\section{Transcription factor binding site (TFBS) analysis}

The specific ABCG2 sequence was used to look into the transcription factor binding site (TFBS) analysis using the MATCH tool (Kel et al., 2003). The TFBS composition was identified through the MATCH tool. Both aspects of TFBS abundance and total TFBS frequency were examined. Four groups of profiles such as immune cellspecific profile, cell cycle-specific profile, muscle-specific profile and liver-specific profile being provided in MATCH tool.

\section{Site-directed mutagenesis}

Mutagenesis experiments were performed using the QuickChange ${ }^{\mathrm{TM}}$ II Site-Directed Mutagenesis kit (Stratagene, USA). Prior to the mutagenesis reaction, two complementary oligonucleotides containing the desired mutation flanked by unmodified nucleotide sequences were synthesized. Inverse PCR was conducted by preparing PCR primers and template plasmid around $10 \mathrm{pmol} / \mu \mathrm{l}$ and $50 \mathrm{ng} / \mu \mathrm{l}$ respectively at first. Subsequently PCR reaction mixture with total volume $20 \mu \mathrm{L}$ in each tube was prepared which containing $14.4 \mu \mathrm{L}$ of PCR grade water, $2 \mu \mathrm{L}$ of 10x Buffer for iPCR, $2 \mu \mathrm{L}$ of $2 \mathrm{mM}$ dNTPs, 0.4 of $\mu \mathrm{L}$ forward primer (5'-CGT GCT TTT ACG AAA CTC GTT CCC G-3') (10 pmol/ $\mu \mathrm{L}), 0.4 \mu \mathrm{L}$ of reverse primer (5'- CAC GTG TTA CGA GCT TAG AAA TGT C-3') (10 $\mathrm{pmol} / \mu \mathrm{L}), 0.4 \mu \mathrm{L}$ of Plasmid Template DNA $(50 \mathrm{ng} / \mu \mathrm{L})$ and $0.4 \mu \mathrm{L}$ of KOD -Plus- DNA Polymerase. Next, the PCR tubes were subjected to thermal cycling for 7 cycles. Around 0.8 to $1 \mu \mathrm{L}$ of $D p n I$ restriction enzymes was added into $20 \mu \mathrm{L}$ PCR reaction and mixed gently by pipetting before it was incubated at $37^{\circ} \mathrm{C}$ for $1 \mathrm{hr}$ to digest the template plasmid. Next, PCR product was self-ligated by preparing the ligation reaction mixture consisting of $2 \mu \mathrm{l}$ of DpnI- treated PCR product, $7 \mu \mathrm{l}$ of PCR grade water, $5 \mu \mathrm{l}$ of Ligation High and $1 \mu \mathrm{l}$ of T4 Polynucleotide Kinase in a new sterile microcentrifuge tube. Each reaction mixture was centrifuged and incubated at $16^{\circ} \mathrm{C}$ for 1 $\mathrm{hr}$ before transformation into XLI-Blue E. coli and plating. DNA sequencing was conducted to analyze and verify transformants (mutants).

\section{RESULTS}

Gradient PCR was conducted to identify the best annealing temperature for the primer designed, ABCG2F 5'ATG GTA CCG CAA GTC ACA CGT TTT TAC CTT CT-3' and ABCG2R 5'- ATG AGC TCT CGA GTC TAT GAT CAA AA AGC GT-3'. The PCR product was yielded at optimum annealing temperature of $61.4^{\circ} \mathrm{C}$. A single PCR amplicon band, which is about 1,500 bp in size (Figure 1) and close to the expected size, was observed on $1 \%$ agarose gel following PCR purification. 


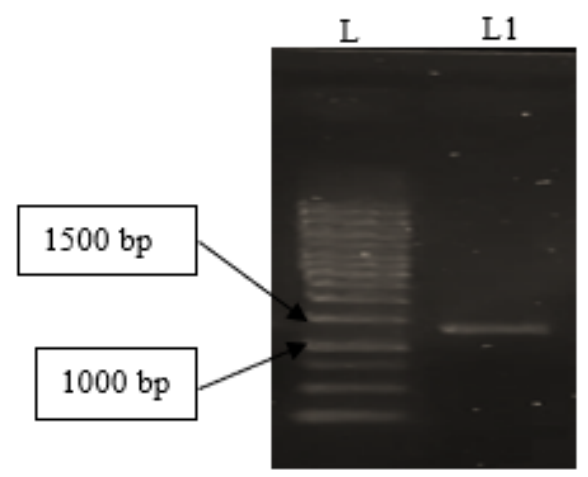

Figure 1. Agarose gel electrophoresis was conducted using 1\% agarose gel and showed a band after PCR purification. First lane from the left (Lane L) was loaded with $1 \mathrm{~kb}$ DNA ladder (Promega, USA) while the band in the second lane (L1) represents PCR amplicon produced at $61.4^{\circ} \mathrm{C}$ annealing temperature.

Study and analysis of TFBS were conducted using MATCH program. Based on bar chart in Figure 2, the frequency of sites per nucleotide across four profiles (liver-specific profile, immune cell-specific profile, musclespecific profile and cell cycle-specific profile) depicts that majority of TFBS per nucleotide were located in liverspecific profile, which accounted for 0.0913 in frequencies and comprised of TFBS composition such as AP-1 (Figure 3). Muscle-specific profile showed the least number of sites per nucleotide, which was only 0.0187. Overall, immune cell-specific profile had more composition of TFBS than other types of profiles, these TFBSs were AP-1, GATA-3, TATA and NF-AT. On the other hand, the highest amount of TFBS across the four profiles was HNF-3beta.

The 1196/1215 identities (98\% similarities) were obtained after blasting the mutated zebrafish ABCG2 gene promoter (Supplementary Figure 1) against NCBI database. The 0.0 E-value is a good indication that the expected occurrences by chance of this alignment with the query sequence in the database is zero. About $0 \%$ gap indicates the absence of any frameshift mutations.

Furthermore, MATCH program showed that after site-directed mutagenesis the AP-1 is located at a different position than previous unmutated sequence. Based on Figure 5, position $1113 \mathrm{bp}$ of the forward strand does not depict any presence of TFBS after targeted AP-1 TFBS (with base TGACGCG) was deleted, indicating mutation was successful.

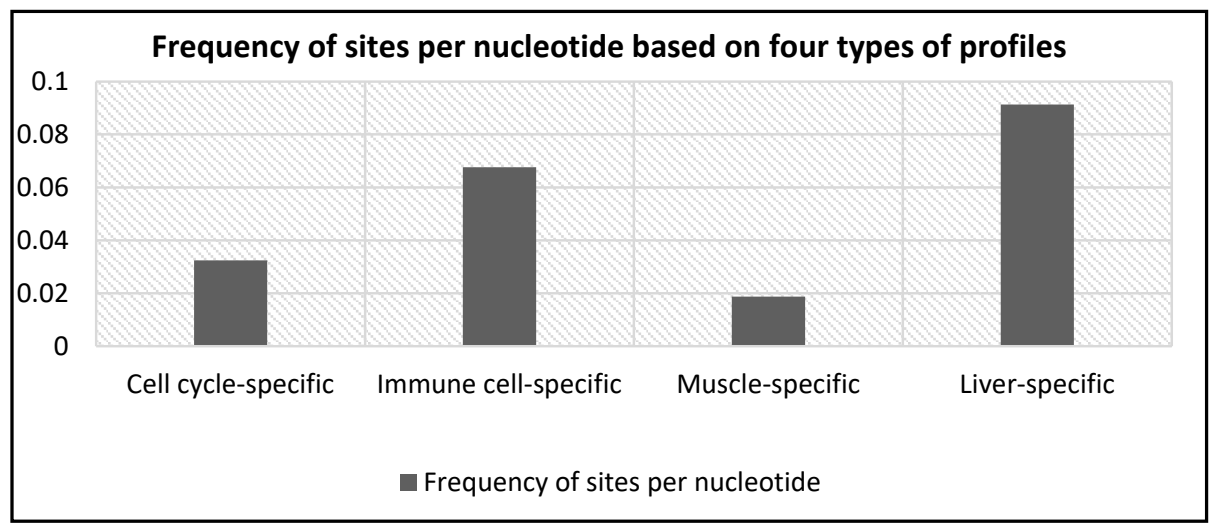

Figure 2. The expected number of TFBS compositions found in $1.5 \mathrm{~kb}$ promoter sequence across four types of profiles estimated based on standard TRANSFAC profiles via public MATCH program. 


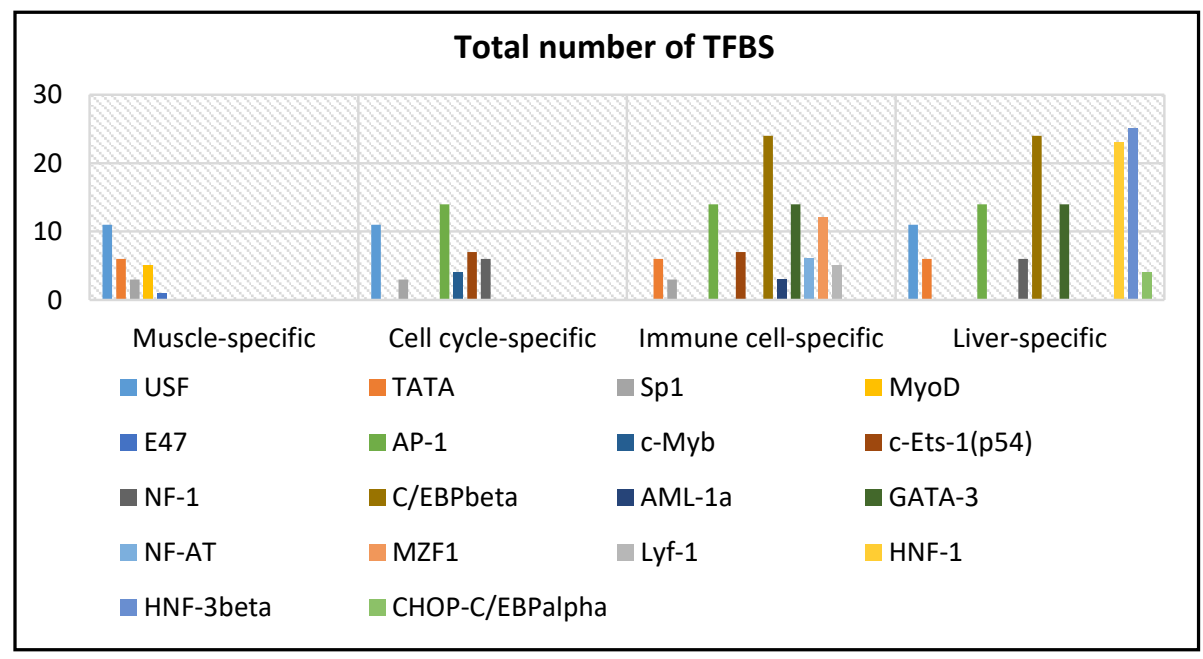

Figure 3. The expected number of TFBS compositions found within ABCG2 gene promoter of zebrafish across four types of profiles.

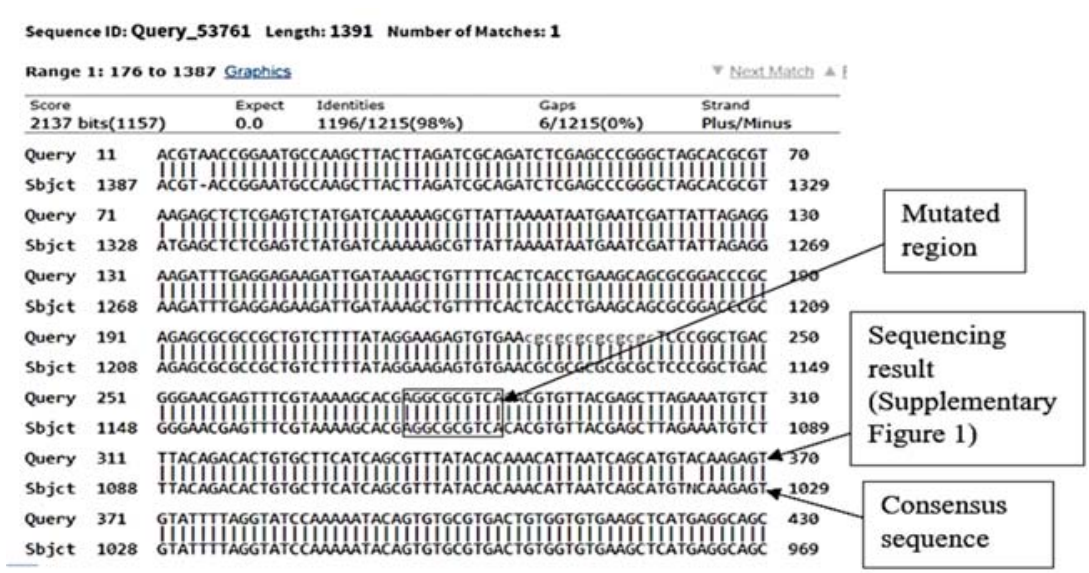

Figure 4. BLAST pairwise alignment results showing the reverse sequences of mutated zebrafish $A B C G 2$ gene promoter as query and the Danio rerio chromosome 23 (GenBank accession number: LR812085.1) as the closest match.

\begin{tabular}{|c|c|c|c|c|c|}
\hline $\begin{array}{l}\text { matrix } \\
\text { identifier }\end{array}$ & $\begin{array}{l}\text { position } \\
\text { (strand) }\end{array}$ & $\begin{array}{l}\text { core } \\
\text { match }\end{array}$ & $\begin{array}{l}\text { matrix } \\
\text { match }\end{array}$ & $\begin{array}{l}\text { sequence (always the } \\
(+) \text {-strand is shown) }\end{array}$ & factor name \\
\hline$\underline{V} \$$ CEBPB -02 & $1088(+)$ & 0.996 & 0.886 & 6 ctcTTGCTatacaa & C/EBPbeta \\
\hline V\$HNF $3 B$ & $1096(-)$ & 1.000 & 0.840 & o atacaAAATAtgata & HNF-3beta \\
\hline$\underline{\mathrm{V} \$ \mathrm{HNF} 1 \mathrm{C}}$ & $1106(t)$ & 0.772 & 0.650 & o tGATAGaaaataatggt & HNF-1 \\
\hline V\$HNF $3 B$ & $1108(-)$ & 1.000 & 0.860 & b atagaAAATAatggt & HNF-3beta \\
\hline V\$NNF1 1 & $1122(+)$ & 0.777 & $7 \quad 0.670$ & tGGTACgatttcttaa & HNF-1 \\
\hline VDCEBPB 02 & $1128(t)$ & 0.861 & 10.880 & gaatTTCTtaatta & $\overline{C / E B P b e t a}$ \\
\hline V\$NF1 06 & $1156(+)$ & 1.000 & 0.952 & 2 tcTTGGCggcecctggat & $\mathrm{NF}-1$ \\
\hline V\$AP1_O4 & $1169(-)$ & 0.935 & $\begin{array}{ll}5 & 0.853\end{array}$ & 3 tggaTGTCAgg & $A P-1$ \\
\hline V\$GATA3 03 & $1181(+)$ & 1.000 & 0.920 & tttgatctta & $\overline{\text { GATA }-3}$ \\
\hline V\$GATA3 03 & $1181(-)$ & 0.977 & 70.938 & ttTGATCtta & $\overline{\text { GATA }-3}$ \\
\hline
\end{tabular}

Figure 5. Part of the TFBS list showing the deletion of targeted bases. The targeted AP-1 TFBS is missing from the position 1113 bp (forward strand), indicating the successful mutation. 


\section{DISCUSSION}

In this study, 5'- TGACGCG -3' was chosen as the site to be mutated which is at expected position (forward strand) from $1113 \mathrm{bp}$ to $1122 \mathrm{bp}$ of the $A B C G 2$ gene. Based on the MATCH program, activating protein-1 (AP-1) TFBS is located at this deleted region. The primers were designed for the amplification of mutated $A B C G 2$ gene and deletion was the type of mutation selected. The constitution of AP-1 comprises multiple proteins (Jun, Fos and ATF) involved in cell proliferation (Karin, Liu, \& Zandi, 1997). AP-1 acts to receive extracellular signals and participates in induce proliferation and differentiation of cells. This transcription factor influences breast cancer cell growth with the involvement of modulating cyclin D1 and restrains the activation of E2F (Shen et al., 2007). Tam67 (a dominant form of c-Jun and part of Jun family members) makes up the structure of the AP-1 transcription factor and it is capable of hindering the development of breast cancer cells by restricting the activity of AP-1 (Gazon, Barbeau, Mesnard, \& Peloponese, 2018; Lu et al., 2005).

Another essential component of AP-1 is the Fos family which comprises Fosb and c-Fos. c-Fos is found to be associated in a dual way of causing diseases. High expression of this protein induces proliferation of osteoblasts and malignant tumours of bone occurrences while its removal resulted in serious effects on bone resilience and strength (Schinke \& Karsenty, 2008). Breast cancer is not the only cancer studied linked to the transcription factor AP-1. AP-1 is also a protein responsible for regulating gene transcription associated with the cause of cervical cancer. However, curcumin, an antioxidative agent, has been described in previous study to have the ability to modulate the human papillomaviruses (HPVs) such as HPV18 (Prusty \& Das, 2005).

Verification on the mutated sequence has been conducted using BLAST and high similarities (97\%) with Danio rerio's linkage group 23 were detected at $0 \%$ gap. Subsequently, further verification on mutated amplicon has been conducted by aligning the reverse sequences of mutated zebrafish ABCG2 gene promoter with Danio rerio chromosome 23 (Accession number: LR812085.1) via BLAST. Comparison between consensus sequence (non-mutated sequence) and new sequencing result (mutated sequence) gives high similarities at around $98 \%$ with E-value of 0.0. Previously, the non-mutated promoter region of $A B C G 2$ possesses the binding site for transcription factor AP-1 which is located at $1113 \mathrm{bp}$ from the TSS +1 of the gene. However, after inserting a new sequence (mutated sequence), results reveal no presence of AP-1 binding site at position $1113 \mathrm{bp}$ from the TSS +1 of the gene. That means the sequence has been successfully mutated and can be used for further expression analysis and functional studies. It is expected that the deleted AP-1 TFBS will cause significant reduction in zebrafish ABCG2 promoter activity as it has been proven by various literature that AP-1plays vital roles in both enhancer and promoter activity (Grossman et al., 2017; Kerppola \& Curran, 1993; Lim et al., 2019b).

\section{CONCLUSION}

One of the TFBSs, AP-1, was found in a 1.5kb zebrafish ABCG2 promoter sequence through the MATCH program and was successfully mutated using the QuickChange ${ }^{\mathrm{TM}}$ II Site-Directed Mutagenesis kit (Stratagene, USA). This will aid in further research on multidrug resistance mechanism of breast cancer which thus be part of target for chemotherapeutic agent in the future.

\section{ACKNOWLEDGEMENTS}

This research is wholly sponsored by the Resource Biotechnology teaching allocation fund from the Faculty of Resource Science and Technology, Universiti Malaysia Sarawak as well as the research grant by The Ministry of Higher Education, Malaysia through Fundamental Research Grant Scheme with grant number F07/FRGS/1872/2019 awarded to H. H. Chung. 


\section{REFERENCES}

Andersen, V., Vogel, L. K., Kopp, T. I., Sæbø, M., Nonboe, A. W., Hamfjord, J., Kure, E. H., \& Vogel, U. (2015). High ABCC2 and Low ABCG2 Gene Expression Are Early Events in the Colorectal Adenoma-Carcinoma Sequence. Plos One, 10(3), 1-13.

Chung, H. H. (2018). Real-time polymerase chain reaction (RT-PCR) for the authentication of raw meats. International Food Research Journal, 25(2), 632-638.

Gazon, H., Barbeau, B., Mesnard, J.-M., \& Peloponese, J.-M. (2018). Hijacking of the AP-1 Signaling Pathway during Development of ATL. Frontiers in Microbiology, 8, 2686.

Grossman, S. R., Zhang, X., Wang, L., Engreitz, J., Melnikov, A., Rogov, P., Tewhey, R., Isakova, A., Deplancke, B., Bernstein, B. E., \& Mikkelsen, T. S. (2017). Systematic dissection of genomic features determining transcription factor binding and enhancer function. Proceedings of the National Academy of Sciences, 114(7), E1291-E1300. doi:10.1073/pnas.1621150114

Hernandez-Garcia, C. M., \& Finer, J. J. (2014). Identification and validation of promoters and cis-acting regulatory elements. Plant Science, 217, 109-119.

Hu, J., Zhang, H., Liu, L., Han, B., Zhou, G., \& Su, P. (2020). TRPS1 Confers Multidrug Resistance of Breast Cancer Cells by Regulating BCRP Expression. Frontiers in Oncology, 10, 934. doi: $10.3389 /$ fonc. 2020.00934

Jee, M. S., Lim, L. W. K., Dirum, M. A., Hashim, S. I., Masri, M. S., Tan, H. Y., Lai, L. S., Yeo, F. K. S., \& Chung, H. H. (2017). Isolation and characterization of avirulence genes in Magnaporthe oryzae. Borneo Journal of Resource Science and Technology, 7(1), 31-42.

Karin, M., Liu, Z.-G., \& Zandi, E. (1997). AP-1 function and regulation. Current Opinion in Cell Biology, 9(2), 240-246.

Kel, A. E., Gössling, E., Reuter, I., Cheremushkin, E., Kel-Margoulis, O. V., \& Wingender, E. (2003). MATCH: A tool for searching transcription factor binding sites in DNA sequences. Nucleic Acids Research, 31(13), 3576-3579.

Kerppola, T. K., \& Curran, T. (1993). Selective DNA bending by a variety of bZIP proteins. Molecular and Cell Biology, 13(9), 5479-5489.

Kobayashi, I., Saito, K., Moritomo, T., Araki, K., Takizawa, F., \& Nakanishi, T. (2008). Characterization and localization side population (SP) cells in zebrafish kidney hematopoietic tissue. Blood, 111(3), 1131-1137.

Lim, L. W. K., \& Chung, H. H. (in press). Functional characterization of ABCB4, ABCC1 and ACBG2 gene promoters in zebrafish (Danio rerio) embryos via microinjection reveal spatiotemporal xenobiotic multidrug resistance evidences. Gene Reports.

Lim, L. W. K., Chung, H. H., \& Hussain, H. (2020). Organellar genome copy number variations and integrity across different organs, growth stages, phenotypes and main localities of sago palm (Metroxylon sagu Rottboll) in Sarawak. Gene Reports, 21, 100808. https://doi.org/10.1016/j.genrep.2020.100808.

Lim, L. W. K., Tan, H. Y., Aminan, A. W., Jumaan, A. Q., Moktar, M. Z., Tan, S. Y., Balinu, C. P., Robert, A. V., Chung, H. H. and Sulaiman, B. (2018a). Phylogenetic and expression of ATP-binding cassette transporter genes in Rasbora sarawakenesis. Pertanika Journal of Tropical Agricultural Science, 41(3), $1341-1354$

Lim, L. W. K., Chung, H. H., Chong, Y. L., \& Lee, N. K. (2018b). A survey of recently emerged genome-wide computational enhancer predictor tools. Computational Biology and Chemistry, 74(1), 132-141.

Lim, L. W. K., Chung, H. H., Chong, Y. L., \& Lee, N. K. (2019a). Enhancers in proboscis monkey: A primer. Pertanika Journal of Tropical Agricultural Science, 42(1), 261-276.

Lim, L. W. K., Chung, H. H., Chong, Y. L., \& Lee, N. K. (2019b). Isolation and characterization of putative liverspecific enhancers in proboscis monkey (Nasalis larvatus). Pertanika Journal of Tropical Agricultural Science, 42(2), 627-647.

Liu, R., \& States, D. J. (2002). Consensus promoter identification in the human genome utilizing expressed gene markers and gene modeling. Genome Research, 12(3), 462-469.

Lu, C., Shen, Q., Dupré, E., Kim, H., Hilsenbeck, S., \& Brown, P. H. (2005). cFos is critical for MCF-7 breast cancer cell growth. Oncogene, 24(43), 6516-6524.

Maciejczyk, A1., Szelachowska, J., Ekiert, M., Matkowski, R., Hałoń, A., \& Surowiak, P. (2012). Analysis of BCRP expression in breast cancer patients. Ginekologia Polska, 83(9), 681-687. 
Mishra, A., Dhanda, S., Siwach, P., Aggarwal, S., \& Jayaram, B. (2020). A novel method SEProm for prokaryotic promoter prediction method based on DNA structure and energetics. Bioinformatics, 36(8), 2375-2384.

Mo, W., \& Zhang, J. T. (2012). Human ABCG2: structure, function, and its role in multidrug resistance. International Journal of Biochemistry and Molecular Biology, 3(1), 1-27.

Prusty, B. K., \& Das, B. C. (2005). Constitutive activation of transcription factor AP-1 in cervical cancer and suppression of human papillomavirus (HPV) transcription and AP-1 activity in HeLa cells by curcumin. International Journal of Cancer, 113(6), 951-960.

Schinke, T., \& Karsenty, G. (2008). Transcriptional Control of Osteoblast Differentiation and Function. Principles of Bone Biology, 1, 109-119.

Shen, Q., Uray, I. P., Li, Y., Krisko, T. I., Strecker, T. E., Kim, H.-T., \& Brown, P. H. (2007). The AP-1 transcription factor regulates breast cancer cell growth via cyclins and E2F factors. Oncogene, 27(3), 366377.

Sukowati, C. H., Rosso, N., Pascut, D., Anfuso, B., Torre, G., Francalanci, P., Crocè, L. S., \& Tiribelli, C. (2012). Gene and functional up-regulation of the BCRP/ABCG2 transporter in hepatocellular carcinoma. BMC Gastroenterology, 12(1), 1-8.

Wang, S., Cheng, X., Li, Y., Wu, M., \& Zhao, Y. (2018). Image-based promoter prediction: A promoter prediction method based on evolutionarily generated patterns. Scientific Reports, 8, 17695.

Yip, C., Bhoo, PN., \& Teo, S. (2014). A review of breast cancer research in Malaysia. Medical Journal of Malaysia, 69, 8-112. 